\title{
CHAPTER 23 \\ Public Health Co-benefits of Reducing Greenhouse Gas Emissions
}

\author{
Qiyong Liu and Jinghong Gao
}

Summary The public health co-benefits that curbing climate change would have may make greenhouse gas (GHG) mitigation strategies more attractive and increase their implementation. The primary purpose of this chapter is to review the evidence on GHG mitigation measures and the related health co-benefits; identify potential mechanisms, uncertainties, and knowledge gaps; and provide recommendations to promote further development and implementation of climate change response policies at both national and global levels. Evidence of the effects of GHG abatement measures and related health co-benefits has been observed at regional, national, and global levels, involving both low- and high-income societies. GHG mitigation actions have mainly been taken in five sectors - energy generation, transport, food and agriculture, households, and industry—consistent with the main sources of GHG emissions. GHGs and air pollutants to a large extent stem from the same sources and are inseparable in terms of their atmospheric evolution and effects on ecosystems; thus, reductions in GHG emissions are usually, although not always, estimated to have cost-effective co-benefits for public health. Some integrated mitigation strategies involving multiple sectors, which tend to create greater health benefits, have also been investigated, and this chapter discusses the pros and cons of different mitigation measures, issues with existing knowledge, priorities for

\footnotetext{
Q. Liu $(\bowtie)$

State Key Laboratory of Infectious Disease Prevention and Control, Collaborative Innovation Center for Diagnosis and Treatment of Infectious Diseases, National Institute for Communicable Disease Control and Prevention, Chinese Center for Disease Control and Prevention, Beijing, China

Shandong University Climate Change and Health Center, School of Public Health, Shandong University, Jinan, Shandong, China

e-mail: liuqiyong@icdc.cn

J. Gao

The First Affiliated Hospital of Zhengzhou University, Zhengzhou, Henan, China

National Engineering Laboratory for Internet Medical Systems and Applications, Zhengzhou, Henan, China

e-mail: fccgaojh@zzu.edu.cn
} 
research, and policy implications. Findings from this study can play a role not only in motivating large GHG emitters to make decisive changes in GHG emissions, but also in facilitating cooperation at international, national, and regional levels to promote GHG mitigation policies that protect public health from climate change and air pollution simultaneously.

\section{Climate Change}

There is robust evidence that climate change is occurring and that anthropogenic greenhouse gas (GHG) emissions, primarily from human activity-related burning of fossil fuels, are the main drivers (Stocker et al., 2013). According to the Fifth Assessment Report (AR5) from the Intergovernmental Panel on Climate Change (IPCC), the evidence of climate change is unequivocal. During the period 1880-2012, there was a warming of $0.85^{\circ} \mathrm{C}$ in the global average surface temperature (Pachauri et al., 2014a; Stocker et al., 2013). Without further mitigation actions, the average temperature may rise by $2.6-4.8^{\circ} \mathrm{C}$ by the end of this century (Watts et al., 2015). In addition, it has been suggested that even if $\mathrm{CO}_{2}$ emissions abruptly ceased, climate change would continue for hundreds of years because of the inertia in the global climate system (Solomon et al., 2009).

Anthropogenic GHG emissions-primarily from human activity-related energy generation, transport, food and agriculture, household, and industrial processesare considered the main driver of climate change (Pachauri et al., 2014a; Stocker et al., 2013). In order to hold the increase in the global average temperature to less than $2{ }^{\circ} \mathrm{C}$ relative to preindustrial levels to avoid the risk of potentially catastrophic climate change impacts, it was reported that total anthropogenic $\mathrm{CO}_{2}$ emissions needed to be kept below 2900 billion tonnes (Gt) by the end of this century (Watts et al., 2015; Whitmee et al., 2015). However, in the years 2003-2011, an average global annual emissions growth rate of $3 \%$ per year was observed, whereas the growth figure over the 1980-2002 period was 1.2\% annually (Netherlands Environmental Assessment Agency, 2007). In 2014, emissions from the combustion of fossil fuels and industrial processes totaled $35.7 \mathrm{Gt}$ of $\mathrm{CO}_{2}$, with current trends expected to exceed the required emissions target over the next 15-30 years (Watts et al., 2015).

\section{Health Effects of Climate Change}

The health of human beings is sensitive to shifts in weather patterns and other changes in climate systems (e.g., temperature, precipitation, and occurrence of extreme weather events) (Smith et al., 2014). To date, converging evidence from different lines of research generally suggests that climate change, both directly and indirectly, has already started to damage human health and is expected to cause increasingly adverse impacts in the future (Field et al., 2014; Pachauri et al., 2014b; 


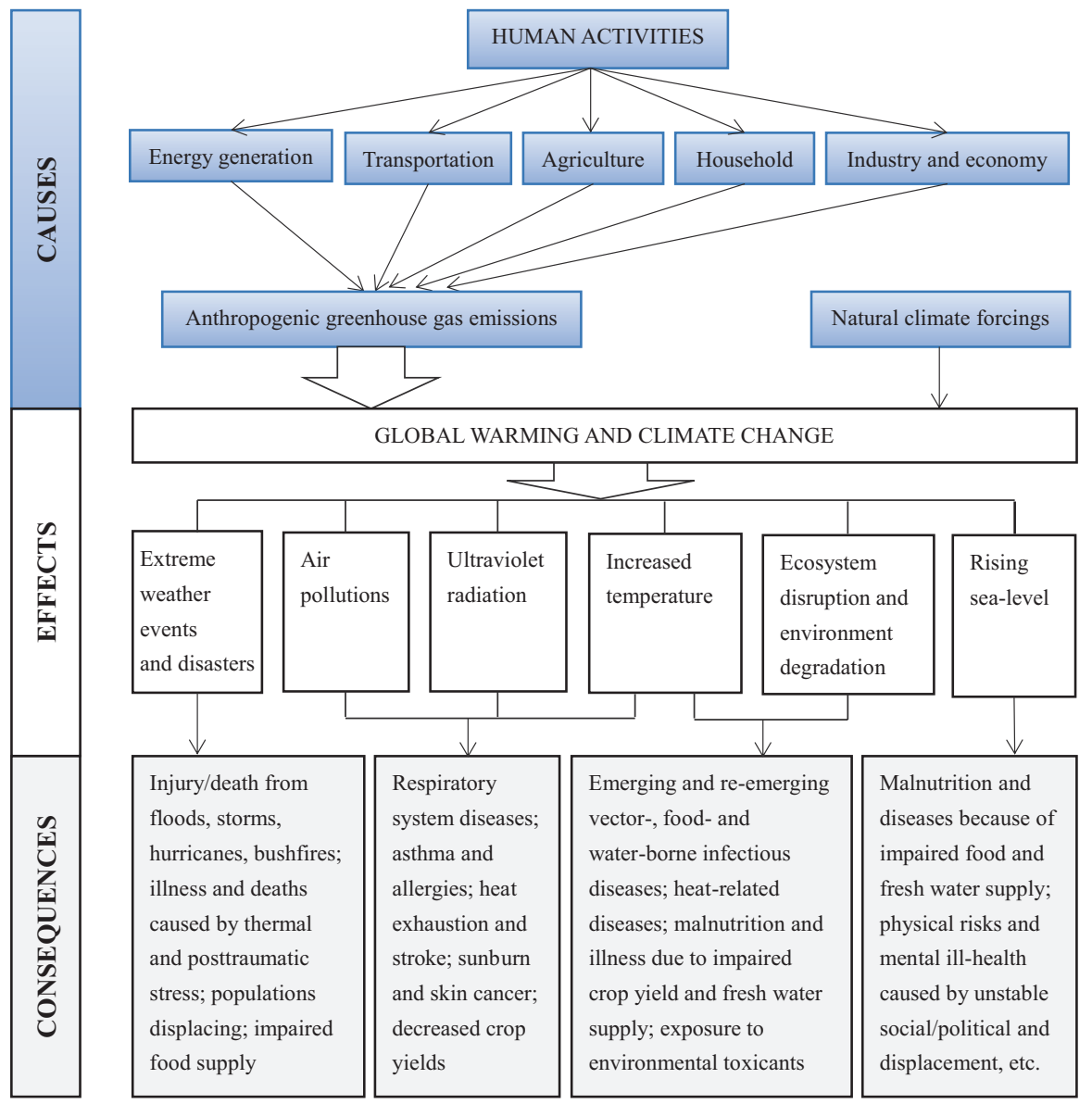

Fig. 23.1 Schematic summary of climate change determinants and potential pathways through which climate change affects human health

Patz et al., 2008; Smith et al., 2014). Climate change can affect public health via various pathways (Fig. 23.1) (Field et al., 2014). Directly, climate change can increase the frequency and intensity of extreme weather events such as heat waves, floods, droughts, and other weather-related natural disasters, which will lead to increased injury, morbidity, and mortality, especially for vulnerable populations (Field et al., 2014; IPCC, 2007; Smith et al., 2014). Indirectly, health impacts may result from climate change-related ecosystem alterations and environmental degradation, as well as the corresponding decline in air quality and impairment of fresh water and food supplies, which, in turn, influence the distribution and incidence of water-, food-, and vector-borne infectious diseases and respiratory system diseases, and can degrade nutritional status (Barros et al., 2014; Field et al., 2014; Patz et al., 2008; Smith et al., 2014). In addition, climate change may play a role in other less 
direct health outcomes by mediating societal systems. These outcomes include physical risks and mental illness caused by unstable social or political status, violent conflict, and population displacement associated with rising sea levels (Barros et al., 2014; IPCC, 2007; Pachauri et al., 2014b); malnutrition due to impaired crop yields and food insecurity due to ecosystem disruption and rising sea levels (Barros et al., 2014; Pachauri et al., 2014b); and loss of workforce, economy, and health care systems due to extreme weather events (Field et al., 2014; Pachauri et al., 2014a; Smith et al., 2014).

If no further climate change mitigation actions are undertaken, the combined effects of the selected impacts on the global annual gross domestic product (GDP) are expected to rise over time to likely levels of $1.0-3.3 \%$ by 2060, with the largest negative economic consequences being suffered by regions in Africa and Asia (Organization for Economic Co-operation and Development (OECD), 2015). Climate change has been described as the biggest global threat confronting public health in the twenty-first century (Costello et al., 2009).

\section{Existing Response and Challenges}

Although there are now several policy initiatives, lifestyle and other recommendations, and technology instruments that can help mitigate climate change (Pachauri et al., 2014b; Smith et al., 2014; Watts, 2009; Xia et al., 2015), many countries (especially developing countries) remain reluctant to make decisive changes (Edenhofer et al., 2014a). Of the worldwide efforts to reduce GHG emissions, active participation and decisive actions of developing countries are essential to limit the increase in GHG concentrations and prevent dangerous anthropogenic interference with the climate system (Pachauri et al., 2014a). However, developing nations are concentrating so much on economic development, air quality improvement, and poverty reduction that they have limited economic resources and allocate a low priority on their political agenda to tackling the challenges posed by GHG emissions and climate change (Barros et al., 2014; Field et al., 2014). Additionally, developing countries often insist that the "common but shared responsibility" principle of the 1992 United Nations Framework Convention on Climate Change (UNFCCC) should be applied, meaning they should not have the same obligations to reduce GHG emissions as developed countries until they have achieved certain level of human development (Costa, Rybski, \& Kropp, 2011). Low- and middle-income countries point out that they are only retracing the same development path taken in the past by present-day high-income countries. This highlights the worldwide challenge of balancing environmental and public health concerns against economic growth. Thus, the issue of how to balance countries' rights to sustainable development and economic growth-especially the rights of developing nations-with enforceable reductions in GHG emissions may be the key challenge of ambitious global mitigation action (Watts et al., 2015). 


\section{The Potential Opportunity: Public Health Co-benefits of Reducing GHG Emissions}

According to the IPCC, mitigation strategies not only act to curb the emissions of climate-warming pollutants (mainly GHGs) but also, if well chosen and implemented, deliver substantial simultaneous improvements in public health, independent of the effects on climate change, with most of these impacts being beneficial (Field et al., 2014; Gao et al., 2018a; Pachauri et al., 2014a; Smith et al., 2014). A series of studies published in The Lancet has also shown that appropriate climate change mitigation strategies (mainly targeting reductions in GHG emissions) can have additional, independent, and largely beneficial effects on public health (Watts, 2009). For example, actions like reducing fossil fuel combustion and improving energy efficiency, aimed primarily at cutting GHG emissions, can also produce ancillary health benefits from decreased air pollution (West et al., 2013). One of the mechanisms of these so-called health co-benefits of mitigation measures is that GHGs and air pollutants are, to a large extent, emitted from the same sources and are interlinked in terms of their atmospheric behavior and effects on the ecosystem and human beings (Fig. 23.2) (Haines et al., 2009; Lelieveld et al., 2015; Pachauri et al., 2014a; Stocker et al., 2013). Moreover, some air pollutants such as black carbon $(\mathrm{BC})$ and ozone $\left(\mathrm{O}_{3}\right)$ are also greenhouse gas pollutants (climate-warming agents) with even higher radiative forcing (RF) per unit than $\mathrm{CO}_{2}$ (Stocker et al., 2013).

These so-called co-benefits from simultaneously curbing climate change and improving ancillary public health may make GHG mitigation strategies more attractive to developed and developing countries, and may encourage their implementation (Edenhofer et al., 2014a; Field et al., 2014; Shindell et al., 2012). They also bridge the development gap between high- and low-income countries and thus can play an important role in future international negotiations on the climate convention (e.g., the Conference of the Parties) (Haines et al., 2009; Watts, 2009). At the very least, co-benefits can reduce the costs of taking actions against climate change (under certain conditions, the value of health gains may be comparable to or exceed

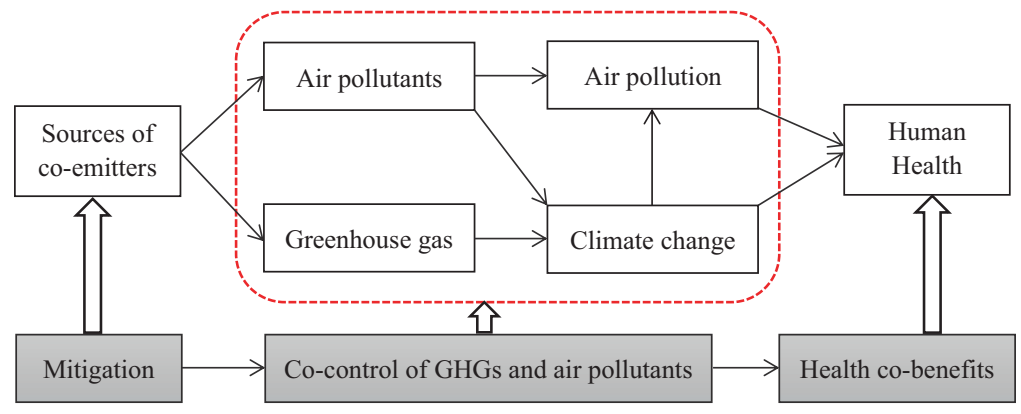

Fig. 23.2 Potential mechanisms and pathways through which reductions in greenhouse gas (GHG) emissions result in public health co-benefits 
abatement costs) and therefore can strengthen the case for climate change mitigation policies in the face of scientific uncertainty (Nemet, Holloway, \& Meier, 2010).

Thus, with a view to filling some of the knowledge gaps on the topic of GHG emissions and related mitigation measures, the main purposes of this study are to (1) synthesize the current evidence of the public health co-benefits of reducing GHG emissions to improve our understanding of the economic sectors involved in GHG mitigation measures, how and through which pathways reductions in GHG emissions can bring ancillary health benefits (mechanisms), and the relevant uncertainties and knowledge gaps associated with the process of assessing health co-benefits; and (2) discuss the potential policy implications.

\section{Public Health Co-benefits of Measures to Mitigate GHG Emissions}

Here, we define public health co-benefits as measures to reduce the emissions of climate-warming pollutants (mainly GHGs), which also hold the potential to simultaneously deliver significant improvements in human health, independent of the effects on climate change. Although there are intersections and overlaps, the associations between reductions in GHG emissions and health co-benefits are based almost entirely on modeling studies and are drawn primarily from five sectors: energy generation and provision, transportation, agriculture and food, households, and industrial and economic processes. According to studies conducted in both high- and low-income countries, GHG mitigation policies in the five domains are often (but not always) estimated to have net co-benefits in terms of public health, and comprehensive measures across various sectors tend to provide greater health benefits. In some cases, the positive health consequences seem to be substantial, cost effective, and attractive to multiple parties (Haines et al., 2009).

The health co-benefits of mitigation measures appear in a number of forms, depending on the sources of the GHG emissions being reduced. The main health co-benefits of reducing GHG emissions in the energy generation sector are linked to the corresponding reductions in common air pollutants (Fig. 23.2), and the most significant pollutants impacted are particulate matter (PM), black carbon (BC), $\mathrm{SO}_{2}$, and nitrogen oxides (NOx) (Crawford-Brown, Barker, Anger, \& Dessens, 2012). In the transportation sector, in addition to the co-control of GHGs and air pollutant emissions, and the health gains from improved air quality (Fig. 23.3), GHG mitigation activities such as active travel can also increase physical activity, social contact, and the opportunity to interact with the natural environment, which may reduce the risks of a range of diseases (e.g., cardiovascular disease, type 2 diabetes, colon and breast cancer, and depression) (Woodcock et al., 2009; Xia et al., 2015). A combination of agricultural technological improvements and reductions in consumption of foods from animal sources in high-consumption populations could provide an effective contribution to meeting targets to reduce GHG emissions and substantially benefit public health-for example, via reductions in type 2 diabetes, ischemic heart 


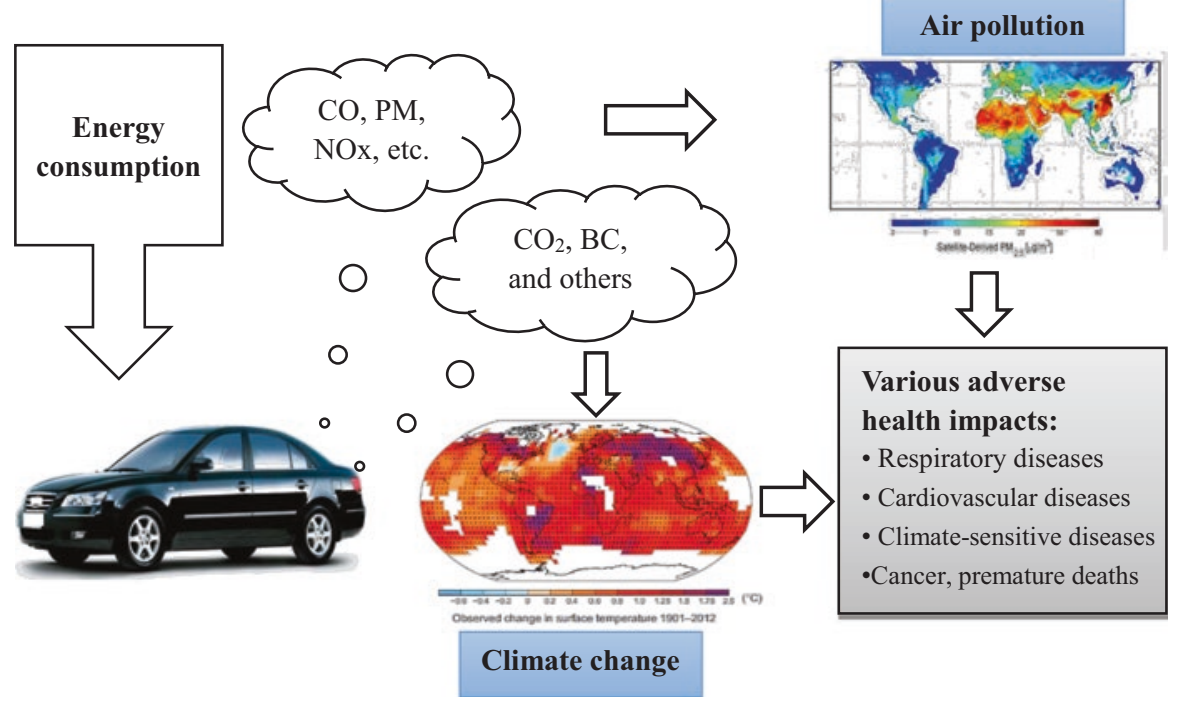

Fig. 23.3 Co-control of greenhouse gas (GHG) and air pollutant emissions and the corresponding health gains due to GHG mitigation measures in the transportation sector (adapted from the work of Chong, Yim, Barrett, \& Boies, 2014). BC black carbon, NOx nitrogen oxides, $P M$ particulate matter

disease, and the prevalence of obesity (Friel et al., 2009; Macdiarmid, 2013). Mitigation actions in the residential and household sector-such as improvements in combustion energy efficiency (Dora, Röbbel, \& Fletcher, 2011), substitution of traditional cooking and space-heating practices with clean fuel technology and lower-emission household appliances (Venkataraman, Sagar, Habib, Lam, \& Smith, 2010; Wilkinson et al., 2009), and energy saving through improvements in fabrics, fuel switching, behavioral changes, etc. (Wilkinson et al., 2009)—could bring about cost-effective health co-benefits (especially for women and children) in addition to reductions in GHG emissions (Anenberg et al., 2013). With regard to industrial and economic processes, co-benefits of GHG abatement, air quality improvements, and health gains could be expected through a series of measures such as improving energy efficiency, promoting the use of clean and renewable energy, and adjusting the industrial energy structure (Crawford-Brown et al., 2012; Gao et al., 2018b).

\section{Challenges and Uncertainties in Estimating Health Co-benefits}

Estimating the full range of the health co-benefits of reducing GHG emissions presents several common challenges to conventional epidemiological approaches and assessment studies (Haines et al., 2009; Pachauri et al., 2014a; Patz et al., 2008; 
Watts et al., 2015), including the following: (1) development of credible scenarios for GHG emissions under "business-as-usual" and mitigation projections over the relevant time course; (2) the fact that rapid development of the energy structure, transportation patterns, land use, building construction, technology innovation, levels of exposure to health drivers, and demographic characteristics (population growth, baseline mortality rates, and value of statistical life) in some societies can change substantially in a short time with major implications for public health; (3) the fact that different subgroups of populations (e.g., age, gender, racial, or socioeconomic groups) may face disproportionate health impacts from air pollution or other health drivers; (4) the large number of health outcomes potentially affected by reductions in GHG emissions; (5) the short- to medium-term and long-term health benefits associated with GHG mitigation actions; (6) the varying lag times between changes in exposure and changes in health outcomes; (7) different economic valuations of health outcomes between developed and nonindustrialized countries; and (8) controversial aspects of key parameters such as discount rates and the terms involved in the concentration-response functions.

\section{Knowledge Gaps}

On the basis of a review of the current literature involving GHG emissions, mitigation strategies, and the related health co-benefits, several knowledge gaps have been identified. First, although several studies have attempted to model or quantify the associations between reductions in GHG emissions and health co-benefits, few studies have tried to establish a thorough performance appraisal system for the evaluation of environmental, socioeconomic, and public health co-benefits in relation to GHG mitigation measures and low-carbon policies (Gao et al., 2018a; Haines et al., 2009; Pachauri et al., 2014b; Smith et al., 2014). It has been indicated that an integrated performance appraisal system, including preimplementation analyses of interventions and follow-up cost-benefit appraisals of program implementation and related results, is crucial to comprehensively assess the performance of specific GHG abatement strategies and could help enhance the efficiency of decision-making processes and help programs to compare and prioritize potential options (McMichael, Barnett, $\&$ McMichael, 2012). Second, to date, most of the health benefit assessments have been performed in developed societies, with insufficient research having been carried out in developing regions, especially in areas like Africa and Asia, where the least GHG emissions are generated while the most severe climate change consequences are suffered (Haines et al., 2009; OECD, 2015; Pachauri et al., 2014b; Smith et al., 2014). These already susceptible areas - affected by conflicts, unstable politics, and impaired water supplies, as well as poor health infrastructure and limited economic resources - may become more vulnerable because of further climate change and the projected increasing frequency and intensity of extreme weather events (Barros et al., 2014; IPCC, 2007; OECD, 2015; Pachauri et al., 2014b; Shindell et al., 2012; West, Fiore, \& Horowitz, 2012; Whitmee et al., 2015). 
In addition, according to the present review, to date there is little evidence in the scientific literature of cost-effectiveness analysis, in practice, of health-promoting interventions to reduce GHG emissions (Haines et al., 2009). Most of the studies are descriptive or modeling investigations, and a conspicuous gap in the scientific research on the health co-benefits of GHG mitigation is the lack of intervention studies and assessments based on actual surveillance data (Pachauri et al., 2014a). Finally, despite potential health benefits of urban green space having been suggested by some studies (Salmond et al., 2016), the quantitative relationships between reductions in GHG emissions associated with green space and human health gains have not been fully evaluated. In order to take advantage of the public health opportunities offered by climate change mitigation measures (Wang \& Horton, 2015), all of these areas for future research need to be explored.

\section{Policy Implications}

To date, although health co-benefits of GHG mitigation strategies in different sectors and countries have been modeled or quantified to a certain extent, their potential to provide cost-beneficial solutions has not been widely recognized, especially in developing nations, and this may hamper international cooperation for global reductions in GHG emissions (Haines et al., 2009; Pachauri et al., 2014a). Therefore, it is crucial to promote education and raise awareness on this topic among policy makers, health professionals, and other stakeholders, particularly in countries and regions confronted with multiple challenges from development, urbanization, population growth, air pollution, and climate change (Haines et al., 2009; Jiang et al., 2013).

Given the complexities of the challenges posed by climate change, major medical associations and nongovernmental health organizations have been calling for integrated multisectoral and multidisciplinary policies and actions to protect human health from dangerous climate change (Edenhofer et al., 2014b; Gao et al., 2018b; Haines et al., 2009). The existing evidence has suggested that comprehensive mitigation strategies generally provide greater health gains and larger reductions in GHG emissions (Friel et al., 2009; Shindell et al., 2012; West et al., 2012; Woodcock et al., 2009). Thus, interdisciplinary mitigation frameworks linking energy generation, transport, agriculture, household, and industrial processes are essential for curbing GHG emissions and improving public health simultaneously. However, we argue that in order to work toward the target of GHG mitigation, joint actions and collaborations - not only by different governmental departments at the national level but also between high- and low-income countries at the international levelare crucial (Edenhofer et al., 2014b; IPCC, 2007; Pachauri et al., 2014b; Whitmee et al., 2015).

In addition, studies have suggested that health professionals could play an important role in combating climate change and GHG emissions. For instance, they could advocate for comprehensive local, national, and international policies to reduce 
GHG emissions and achieve the corresponding health co-benefits (Haines et al., 2009). Professionals can also serve as role models for practices in their own workplaces, communities, and even regions, to help inform and educate the local and national public and policy makers about the health risks posed by climate change and the health co-benefits of GHG mitigation (Watts, 2009).

Although numerous studies have focused on the roles of governments and of various economic sectors in mitigating climate change, relatively limited attention has been paid to the effects of individual behavioral change on reductions in GHG emissions (Gao et al., 2018a; Macdiarmid, 2013). In terms of the potential health co-benefits resulting from behavioral changes-such as limiting car trips in favor of active travel, limiting consumption of foods from animal sources, using loweremission stoves, and reducing energy use-the collective impact of small behavioral changes may result in a considerable reduction in global GHG emissions (Friel et al., 2009; Haines et al., 2009; Venkataraman et al., 2010; Xia et al., 2015).

\section{Conclusion}

This chapter has summarized the available evidence on quantitative associations between reductions in GHG emissions and health benefits. The results generally suggest that GHG mitigation strategies in the energy generation, transport, agriculture and food, household, and industrial sectors could bring ancillary health benefits at the same time, while comprehensive measures across various sectors would tend to provide greater health gains. In addition to raising awareness, the findings of this review can provide valuable information for central and local governments, nongovernmental organizations, and policy makers, as well as for other relevant stakeholders concerned with the development and implementation of low-carbon technologies and policies. Besides, the anticipated cost-effective health co-benefits produced by GHG mitigation actions could make climate change mitigation policies more appealing and true "no-regrets" options for policy makers and GHG emitters, especially in low-income countries with finite economic resources. This could play a key role in motivating large GHG emitters to make voluntary and decisive changes that would help reduce emissions while prioritizing mitigation measures with optimal health gains. It would help in facilitating cooperation and co-action at the international, national, and regional levels on the basis of traditional situations, social expectations, and resource availability to protect human health from dangerous climate change and air pollution simultaneously.

Acknowledgments External funding for this study was obtained from the China Prosperity Strategic Programme Fund (SPF) 2015-16 (Project Code: 15LCI1) and the National Basic Research Program of China (973 Program) (Grant No. 2012CB955504). The funders played no role in the design, development, or interpretation of the present work. The views expressed in this chapter are those of the authors and do not necessarily reflect the position of the funding bodies. The authors also want to thank Alistair Woodward, Sotiris Vardoulakis, Sari Kovats, Paul Wilkinson, Jing Li, Shaohua Gu, and Xiaobo Liu for their kind and constructive suggestions and comments on this chapter. 


\section{References}

Anenberg, S. C., Balakrishnan, K., Jetter, J., Masera, O., Mehta, S., Moss, J., et al. (2013). Cleaner cooking solutions to achieve health, climate, and economic cobenefits. Environmental Science \& Technology, 47, 3944-3952.

Barros, V. R., Field, C. B., Dokken, D. J., Mastrandrea, M. D., Mach, K. J., Bilir, T. E., et al. (2014). IPCC 2014: Climate change 2014: Impacts, adaptation, and vulnerability. Part B: Regional aspects. Contribution of Working Group II to the Fifth Assessment Report of the Intergovernmental Panel on climate change (p. 688). Cambridge, UK and New York, NY: Cambridge University Press.

Chong, U., Yim, S. H., Barrett, S. R., \& Boies, A. M. (2014). Air quality and climate impacts of alternative bus technologies in greater London. Environmental Science \& Technology, 48, 4613-4622.

Costa, L., Rybski, D., \& Kropp, J. P. (2011). A human development framework for CO2 reductions. PLoS One, 6, e29262.

Costello, A., Abbas, M., Allen, A., Ball, S., Bell, S., Bellamy, R., et al. (2009). Managing the health effects of climate change: Lancet and University College London Institute for Global Health Commission. The Lancet, 373, 1693-1733.

Crawford-Brown, D., Barker, T., Anger, A., \& Dessens, O. (2012). Ozone and PM related health co-benefits of climate change policies in Mexico. Environmental Science \& Policy, 17, 33-40.

Dora, C., Röbbel, N., \& Fletcher, E. (2011). Health co-benefits of climate change mitigation: Housing sector. Geneva, Switzerland: Public Health \& Environment Department, Health Security \& Environment Cluster, World Health Organization.

Edenhofer, O., Pichs-Madruga, R., Sokona, Y., Farahani, E., Kadner, S., Seyboth, K., et al. (2014a). Climate change 2014: Mitigation of climate change. Contribution of Working Group III to the Fifth Assessment Report of the Intergovernmental Panel on Climate Change (pp. 511-597). Geneva, Switzerland: IPCC.

Edenhofer, O., Pichs-Madruga, R., Sokona, Y., Farahani, E., Kadner, S., Seyboth, K., et al. (2014b). IPCC 2014: Climate change 2014: Mitigation of climate change. Contribution of working group III to the fifth assessment report of the Intergovernmental Panel on Climate Change. Cambridge, UK and New York, NY: Cambridge University Press.

Field, C. B., Barros, V. R., Dokken, D. J., Mach, K. J., Mastrandrea, M. D., Bilir, T. E., et al. (2014). IPCC 2014: Climate change 2014: Impacts, adaptation, and vulnerability. Part A: Global and sectoral aspects. Contribution of Working Group II to the Fifth Assessment Report of the Intergovernmental Panel on Climate Change (p. 1132). Cambridge, UK and New York, NY: Cambridge University Press.

Friel, S., Dangour, A. D., Garnett, T., Lock, K., Chalabi, Z., Roberts, I., et al. (2009). Public health benefits of strategies to reduce greenhouse-gas emissions: Food and agriculture. Lancet, 374, 2016-2025.

Gao, J., Hou, H., Zhai, Y., Woodward, A., Vardoulakis, S., Kovats, S., et al. (2018a). Greenhouse gas emissions reduction in different economic sectors: Mitigation measures, health co-benefits, knowledge gaps, and policy implications. Environmental Pollution, 240, 683-698.

Gao, J., Kovats, S., Vardoulakis, S., Wilkinson, P., Woodward, A., Li, J., et al. (2018b). Public health co-benefits of greenhouse gas emissions reduction: A systematic review. The Science of the Total Environment, 627, 388-402.

Haines, A., McMichael, A. J., Smith, K. R., Roberts, I., Woodcock, J., Markandya, A., et al. (2009). Health and climate change 6 public health benefits of strategies to reduce greenhouse-gas emissions: Overview and implications for policy makers. Lancet, 374, 2104-2114.

IPCC (2007). Intergovernmental Panel on Climate Change: Fourth assessment report: Climate change 2007: Synthesis report. Geneva, Switzerland: IPCC.

Jiang, P., Chen, Y., Geng, Y., Dong, W., Xue, B., Xu, B., et al. (2013). Analysis of the co-benefits of climate change mitigation and air pollution reduction in China. Journal of Cleaner Production, $58,130-137$. 
Lelieveld, J., Evans, J. S., Fnais, M., Giannadaki, D., \& Pozzer, A. (2015). The contribution of outdoor air pollution sources to premature mortality on a global scale. Nature, 525, 367-371.

Macdiarmid, J. I. (2013). Is a healthy diet an environmentally sustainable diet? Proceedings of the Nutrition Society, 72, 13-20.

McMichael, C., Barnett, J., \& McMichael, A. J. (2012). An ill wind? Climate change, migration, and health. Environmental Health Perspectives, 120, 646-654.

Netherlands Environmental Assessment Agency. (2007). China now no. 1 in CO2 emissions; USA in second position. Bilthoven, The Netherlands: PBL Netherlands Environmental Assessment Agency. Retrieved February 23, 2017, from http://www.pbl.nl/en/dossiers/Climatechange/ Chinanowno1inCO2emissionsUSAinsecondposition

Nemet, G., Holloway, T., \& Meier, P. (2010). Implications of incorporating air-quality co-benefits into climate change policymaking. Environmental Research Letters, 5, 014007.

Organization for Economic Co-operation and Development (OECD). (2015). The economic consequences of climate change. OECD iLibrary: OECD Publishing.

Pachauri, R. K., Allen, M., Barros, V., Broome, J., Cramer, W., Christ, R., et al. (2014a). IPCC 2014: Climate change 2014: Synthesis report. Contribution of Working Groups I, II and III to the Fifth Assessment Report of the Intergovernmental Panel on Climate Change (p. 151). Geneva, Switzerland: IPCC.

Pachauri, R. K., Allen, M., Barros, V., Broome, J., Cramer, W., Christ, R., et al. (2014b). Climate Change 2014: Synthesis report. Contribution of Working Groups I, II and III to the Fifth Assessment Report of the Intergovernmental Panel on Climate Change. Geneva, Switzerland: IPCC.

Patz, J., Campbell-Lendrum, D., Gibbs, H., \& Woodruff, R. (2008). Health impact assessment of global climate change: Expanding on comparative risk assessment approaches for policy making. Annual Review of Public Health, 29, 27-39.

Salmond, J. A., Tadaki, M., Vardoulakis, S., Arbuthnott, K., Coutts, A., Demuzere, M., et al. (2016). Health and climate related ecosystem services provided by street trees in the urban environment. Environmental Health, 15, 36.

Shindell, D., Kuylenstierna, J. C., Vignati, E., van Dingenen, R., Amann, M., Klimont, Z., et al. (2012). Simultaneously mitigating near-term climate change and improving human health and food security. Science, 335, 183-189.

Smith, K. R., Woodward, A., Campbell-Lendrum, D., Chadee, D., Honda, Y., Liu, Q., et al. (2014). Human health: Impacts, adaptation and co-benefits. Climate Change, 709-754.

Solomon, S., Plattner, G.-K., Knutti, R., \& Friedlingstein, P. (2009). Irreversible climate change due to carbon dioxide emissions. Proceedings of the National Academy of Sciences of the United States of America, 106, 1704-1709.

Stocker, T., Qin, D., Plattner, G., Tignor, M., Allen, S., Boschung, J., et al. (2013). IPCC 2013: Climate change 2013: The physical science basis. Contribution of Working Group I to the fifth assessment report of the Intergovernmental Panel on Climate Change (p. 1535). Cambridge, UK and New York, NY: Cambridge University Press.

Venkataraman, C., Sagar, A., Habib, G., Lam, N., \& Smith, K. (2010). The Indian national initiative for advanced biomass cookstoves: The benefits of clean combustion. Energy for Sustainable Development, 14, 63-72.

Wang, H., \& Horton, R. (2015). Tackling climate change: The greatest opportunity for global health. The Lancet, 386, 1798-1799.

Watts, G. (2009). The health benefits of tackling climate change: An executive summary. The Lancet Series 2009, 1-8. https://doi.org/10.1016/S0140-6736(09)61759-1.2

Watts, N., Adger, W. N., Agnolucci, P., Blackstock, J., Byass, P., Cai, W., et al. (2015). Health and climate change: Policy responses to protect public health. Lancet, 386, 1861-1914.

West, J. J., Fiore, A. M., \& Horowitz, L. W. (2012). Scenarios of methane emission reductions to 2030: Abatement costs and co-benefits to ozone air quality and human mortality. Climatic Change, 114, 441-461. 
West, J. J., Smith, S. J., Silva, R. A., Naik, V., Zhang, Y., Adelman, Z., et al. (2013). Co-benefits of mitigating global greenhouse gas emissions for future air quality and human health. Nature Climate Change, 3, 885-889.

Whitmee, S., Haines, A., Beyrer, C., Boltz, F., Capon, A. G., de Souza Dias, B. F., et al. (2015). Safeguarding human health in the Anthropocene epoch: Report of the Rockefeller Foundationlancet commission on planetary health. Lancet, 386, 1973-2028.

Wilkinson, P., Smith, K. R., Davies, M., Adair, H., Armstrong, B. G., Barrett, M., et al. (2009). Public health benefits of strategies to reduce greenhouse-gas emissions: Household energy. Lancet, 374, 1917-1929.

Woodcock, J., Edwards, P., Tonne, C., Armstrong, B. G., Ashiru, O., Banister, D., et al. (2009). Public health benefits of strategies to reduce greenhouse-gas emissions: Urban land transport. Lancet, 374, 1930-1943.

Xia, T., Nitschke, M., Zhang, Y., Shah, P., Crabb, S., \& Hansen, A. (2015). Traffic-related air pollution and health co-benefits of alternative transport in Adelaide, South Australia. Environment International, 74, 281-290.

Open Access This chapter is licensed under the terms of the Creative Commons Attribution 4.0 International License (http://creativecommons.org/licenses/by/4.0/), which permits use, sharing, adaptation, distribution and reproduction in any medium or format, as long as you give appropriate credit to the original author(s) and the source, provide a link to the Creative Commons license and indicate if changes were made.

The images or other third party material in this chapter are included in the chapter's Creative Commons license, unless indicated otherwise in a credit line to the material. If material is not included in the chapter's Creative Commons license and your intended use is not permitted by statutory regulation or exceeds the permitted use, you will need to obtain permission directly from the copyright holder.

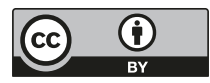

